\title{
Real time monitoring of $B$ cell antigen receptor-proximal events by fluorescence lifetime imaging
}

\author{
M Engelke*1, R Hartig², I Goldbeck1, B Manno', A Stirnweiß2, \\ W Zuschratter ${ }^{3}$, B Schraven ${ }^{2}$ and J Wienands ${ }^{1}$
}

\begin{abstract}
Address: ${ }^{1}$ University of Goettingen, Cellular and Molecular Immunology, Göttingen, Germany, ${ }^{2}$ Otto-von-Guericke University, Molecular and Clinical Immunology, Magdeburg, Germany and ${ }^{3}$ Leibniz-Institut für Neurobiologie, Magdeburg, Germany

* Corresponding author
\end{abstract}

from 12th Joint Meeting of the Signal Transduction Society (STS). Signal Transduction: Receptors, Mediators and Genes

Weimar, Germany. 29-3I October 2008

Published: 26 February 2009

Cell Communication and Signaling 2009, 7(SuppI I):A72 doi:10.1I86/I478-8IIX-7-SI-A72

This abstract is available from: http://www.biosignaling.com/content/7/SI/A72

(c) 2009 Engelke et al; licensee BioMed Central Ltd.

Many molecular events downstream of B cell antigen receptor engagement have been elucidated by different genetic and biochemical approaches. These studies revealed that a hallmark of BCR signalling is the assembly of a multiproteincomlplex comprising at least the SH2 domain-containing adapter protein of $65 \mathrm{kDa}$ (SLP-65), Bruton's tyrosine kinase (Btk) and Phospholipase C- $\gamma 2$ (PLC- $\gamma 2$ ). Only in context of this so called $\mathrm{Ca}^{2+}$ initiation complex PLC- $\gamma 2$ is activated and produces the second messengers Diacylglycerol and Inositol-1,4,5-trisphosphate. Hence, SLP-65 provides a molecular platform that links BCR engagement to the regulation of important transcription factors and the reorganization of the cytoskeleton. However, little is known about the kinetics and subcellular dynamics of $\mathrm{Ca}^{2+}$ initiation complex assembly. Here we report a real time imaging approach to monitor BCR-induced changes in the three dimensional structure of SLP-65. For this aim different dichroic fluorescent SLP-65 variants were expressed in slp65-/- DT40 B cells. In resting cells the conformation of SLP-65 allows for fluorescence resonance energy transfer (FRET) between both fluorophors that was monitored by measuring the fluorescence lifetime of respective donor fluorophors. BCR engagement significantly attenuated the efficiency of FRET indicating an induced conformational change in SLP-65. The kinetics of these changes correlated with that of BCR-induced $\mathrm{Ca}^{2+}$ mobilization.
Hence, this novel approach makes it possible to analyze the spatial and temporal dynamics of BCR-induced $\mathrm{Ca}^{2+}$ initiation complex assembly. 